\title{
ANALISIS IMPLEMENTASI PREPROCESSING DENGAN OTSU-GAUSSIAN PADA PENGENALAN WAJAH
}

\author{
Annahl Riadi ${ }^{1}$, Ruhmi Sulaehani $^{2}$ \\ 1annahlriadi@gmail.com, 2ruhmisulaehani@yahoo.co.id \\ 1,2 Universitas Ichsan Gorontalo
}

\begin{abstract}
Abstrak
Penelitian ini terfokus pada ekspresi wajah untuk deteksi kepuasan pelanggan pada minimarket yang tingkat pelayanannya kurang maksimal. Untuk mengetahui tingkat kepuasan pelanggan dapat dilihat melalui pengenalan wajah yang diambil melalui CCTV pada minimarket tersebut. Permasalahan-permasalahan yang terjadi yaitu banyak pelanggan yang tidak menyampaikan secara langsung kesan yang dirasakan saat berbelanja, sedangkan minimarket dan pusat perbelanjaan harus mengetahui tingkat kepuasan pelanggan untuk meningkatkan strategi penjualan. Penelitian-penelitian untuk menyelesaikan masalah tersebut masih jarang dilakukan. Oleh karena itu, salah satu peran komputasi cerdas adalah untuk menyelesaikan masalah tersebut menggunakan Support Vector Machine (SVM). Tujuan penelitian ini yaitu untuk meningkatkan akurasi dari pengenalan ekspresi wajah pelanggan minimarket melalui perbaikan preprocessing. Hasil penerapan metode otsu dan fungsi gaussian dapat digunakan untuk tahapan preprocessing melalui threshold image yang memiliki kualitas gambar yang baik. Metode otsu-gaussian tidak efektif digunakan untuk preprocessing data yang bersumber dari video atau image dengan kualitas gambar yang kurang baik, sehingga menyulitkan proses pengenalan wajah.
\end{abstract}

Kata kunci: Ekspresi, Wajah, Pelanggan, otsu-gaussian.

\section{Abstract}

In this research, we will focus on facial expressions to detect customer satisfaction in mini markets where the service level is less than optimal. To find out the level of custome satisfaction can be seen through facial recognition tahen through CCTV in the mini market. The problems that occur are many customers who do not directly convey the impression that is felt when shopping, while minimarkets and shopping conters must know the level of customer satisfaction to improve sales strategies. Research to solve the problem is still rerely done, therefore one of the roles of intelligent computing is to solve the problem using Support Vector machine (SVM). The purpose of this study is to improve the accuracy of facial expressions of mini market customers through improved preprocessing. The results of the application of the otsu method and the gaussian function can be used for the preprocessing stage through a threshold image that has good image quality. The otsugaussian method is not effectively used for preprocessing data sourced from video or images with poor image quality, making it difficult to recognize faces.

Keywords: Expression, Face, Customer, otsu-gaussian

\section{Pendahuluan}

Ekspresi wajah merupakah sebuah sinyal sosial yang keluar dan terpancar dari dalam diri manusia yang dapat ditunjukkan melalui banyak hal [1]. Wajah yang telah terdeteksi akan diambil mata dan mulutnya untuk didapatkan informasi di dalamnya. Penelitian ini terfokus pada ekspresi wajah untuk deteksi kepuasan pelanggan pada minimarket yang berada di Kecamatan Marisa Kabupaten Pohuwato yang tingkat pelayanannya dianggap kurang maksimal. Untuk mengetahui tingkat kepuasan pelanggan dapat dilihat melalui pengenalan wajah yang diambil melalui CCTV pada minimarket. Penelitian tentang pengenalan ekspresi wajah secara umum telah dilakukan oleh beberapa peneliti [2][3][4][5]. Dalam penelitian tersebut metode, data dan parameter wajah yang digunakan masing-masing peneliti berbeda sehingga hasil ekspresi wajah beserta akurasi dari hasil penelitian juga berbeda. Teknik pengenalan wajah tidak mudah, oleh karena itu diperlukan tahap pembelajaran (learning) untuk melatih sehingga sistem dapat mengenali wajah yang diuji. Permasalahan umum yang terjadi yaitu banyak pelanggan yang tidak menyampaikan secara langsung kesan yang dirasakan saat berbelanja, sedangkan minimarket dan pusat perbelanjaan harus mengetahui tingkat kepuasan pelanggan untuk meningkatkan strategi penjualan. Berdasarkan beberapa penelitian pengenalan ekspresi wajah, masih terdapat beberapa kekurangan dan kelemahan. Dalam penelitian tersebut dijelaskan bahwa hasil dari evaluasi masih perlu ditingkatkan 
karena kurang optimalnya kinerja dari sistem pengenalan ekspresi wajah yang hanya mengenali ekspresi wajah berdasarkan kondisi mata dan mulut. Ekspresi yang dikenali hanya Netral, Smile dan Sleepy, selain itu jumlah dataset training yang digunakan masih sedikit dan kurang bervariasi [2]. Perlu ditambahkan algoritma untuk menangani permasalahan varians projection yang dinyatakan baik untuk karakter yang saling terpisah, namun bila ada karakter yang terhubung, maka teknik ini bisa digunakan dengan sedikit tambahan algoritma lain [6]. Oleh karena itu hal ini sangat berpengaruh dengan tingkat akurasi yang dihasilkan. Terdapat beberapa mesin pembelajaran untuk klasifikasi citra, seperti Jaringan Syaraf Tiruan, Logika Fuzzy, Algoritma Genetika, dan Support Vector Machine (SVM) [7].

Salah satu algortima yang mampu menyelesaikan masalah klasifikasi dengan baik adalah Support Vector Machine (SVM). Pengenalan ekspresi wajah pengguna E-Learning menggunakan Artificial Neural Network (ANN) dengan fitur ekstraksi Local Binary Pattern (LBP) dan Gray Level CoOccurrence Matrix (GLCM) menemukan bahwa ekspresi wajah yang berhasil dikenali adalah Neutral, Smile/happy, Tired/Sleepy dengan akurasi tertinggi yang didapatkan adalah $88,89 \%$ berdasarkan kondisi mata dan mulut [8]. Support Vector Machine (SVM) adalah suatu teknik klasifikasi yang terbilang baru [6]. Dalam hal klasifikasi, metode SVM sangat popular belakangan ini. SVM berada satu kelas dengan metode ANN (Neural Network) dalam hal fungsi dan kondisi permasalahan yang bisa diselesaikan. Keduanya masuk dalam kelas supervised learning. Baik para ilmuwan dan praktisi telah banyak menerapkan teknik ini untuk menyelesaikan masalah-masalah nyata dalam kehidupan sehari-hari. SVM merupakan metode klasifikasi yang kini banyak dikembangkan dan diterapkan. Metode ini berasal dari teori pembelajaran statistik dan memberikan hasil yang lebih baik dibandingkan dengan metode yang lainnya. SVM bekerja sangat baik pada himpunan data berdimensi tinggi [7]. Walaupun sangat baik dalam menyelesaikan permasalahan klasifikasi, SVM hanya dapat digunakan pada data yang bersifat linier saja, sehingga diperlukan sebuah pengembangan untuk dapat membuat SVM mampu memisahkan data non-linier, salah satunya dengan menambahkan metode yang mampu melakukan klasifikasi dan interpretasi citra.

GLCM telah terbukti menjadi deskriptor tekstur paling kuat yang digunakan dalam analisis citra [6]. GLCM merupakan metode ekstraksi ciri yang menggunakan perhitungan tekstur pada orde kedua yaitu memperhitungkan pasangan dua piksel citra asli, sedangkan pada orde pertama menggunakan perhitungan statistik berdasarkan nilai piksel citra asli dan tidak memperhatikan piksel ketetanggaan [9]. Matriks ko-okurensi adalah salah satu metode statistik yang dapat digunakan untuk analisis tekstur [10]. Tujuan penelitian ini yaitu untuk meningkatkan akurasi dari pengenalan ekspresi wajah pelanggan minimarket melalui perbaikan preprocessing.

\section{Metode}

Konsep dasar preprocessing data dan metode untuk preprocessing data diatur kedalam kategori : pembersihan data, integrasi data dan reduksi data [11]. Sebelum melakukan klasifikasi citra perlu dilakukan tahapan preprocessing terlebih dahulu dengan tahapan dilihat Gambar 1.

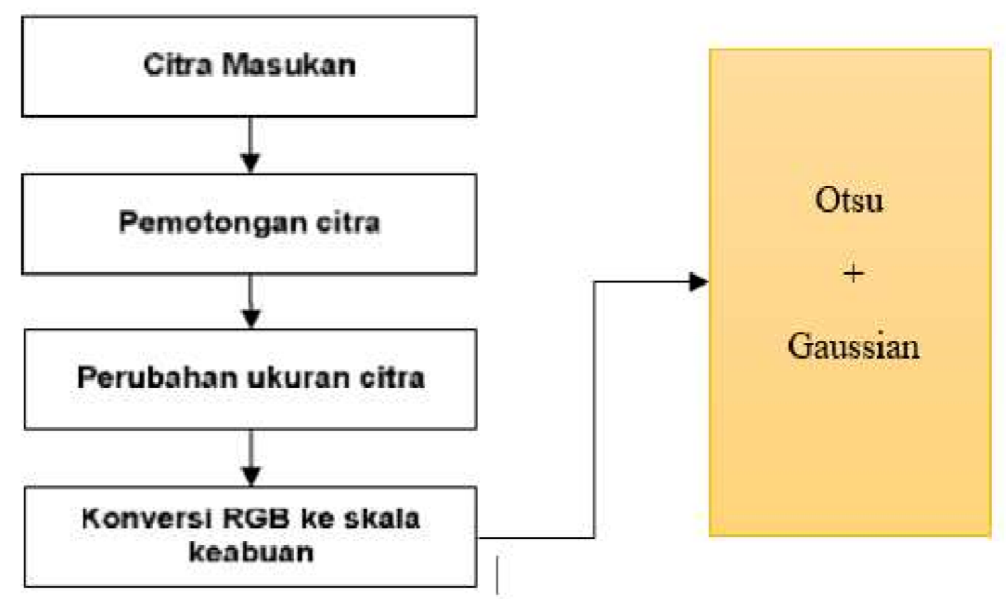

Gambar 1. Tahapan Preprocessing 


\section{Hasil dan Pembahasan Pengumpulan Data}

Penelitian ini menggunakan data gambar dari rekaman CCTV yang ada di DD Mart, data video hasil rekaman CCTV yang diambil dijadikan image agar dapat dilakukan preprocessing, rekaman CCTV yang diambil dari DD Mart yaitu CCTV yang berada di Kasir. Hasil Gambar wajah tersebut kemudian diproses untuk dilakukan pemotongan (cropping) untuk menghasilkan gambar wajah saja. Gambar wajah hasil cropping tersebut kemudian disamakan ukuran gambarnya menjadi 269 x 415 .

\section{Pengolahan awal}

Hasil gambar yang didapat dari proses pengumpulan data menggunakan CCTV tidak menghasilkan kualitas gambar yang baik, jadi untuk memperoleh gambar yang baik penulis membuat rekaman video yang diambil dari ponsel dan direkam langsung di DD Mart Agar wajah pelanggan lebih terlihat jelas. Hal ini dilakukan karena Kualitas gambar yang kurang baik akan memungkinkan ditemukan noise, dimana noise dapat mengurangi akurasi dalam pengenalan wajah pelanggan. Untuk mengatasi hal tersebut gambar wajah dengan model warna RGB yang dinilai kompleks karena menggunakan tiga layer warna, yaitu Red, Green, dan Blue terlebih dahulu di konversi dari warna RGB menjadi grayscale. Dasar warna RGB (Red Green Blue) tidak hanya mewakili warna tetapi juga intensitas cahaya [13].

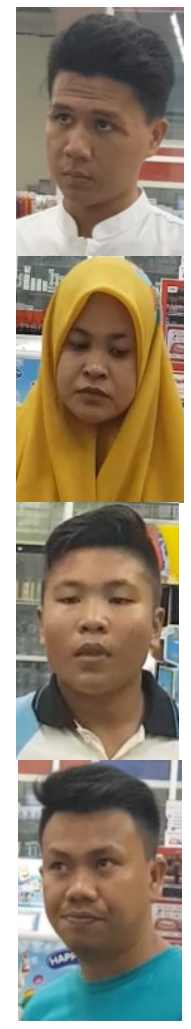

(a)

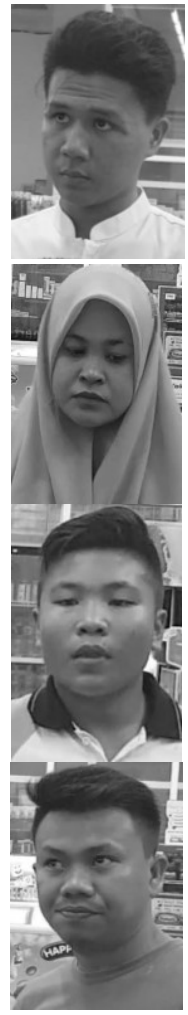

(b)

Gambar 2. Original Image (a), gray Image (b)

\section{Preprocessing}

Metode Otsu merupakan metode yang dianggap popular untuk metode thresholding dan merupakan salah satu teknik bi-level thresholding terhandal [14], sehingga dipakai secara luas untuk mensegmentasi citra [15]. Metode otsu mampu memisahkan antara objek dengan latar belakang sehingga mampu memaksimalkan kecocokan pada tahapan threshold. Metode otsu dengan penambahan fungsi gaussian dapat memperjelas dan meningkatkan nilai dari nilai threshold sebelumnya sehingga menghasilkan warna hitam lebih dominan dan warna putih agak berkurang dari setiap pikselnya. Dalam penelitian ini dapat diperoleh nilai $x$ pada fungsi gaussian dimana jika nilai $x$ 
gaussian diatas 0,5 maka nilai threshold yang diperoleh akan rendah dari original threshold metode otsu, sehingga menghasilkan warna putih akan lebih dominan dan warna hitam semakin berkurang diakibatkan banyaknya gangguan pada image dan atau kualitas gambar yang buruk. Gambar hasil threshold Otsu dan Otsu-Gaussian:

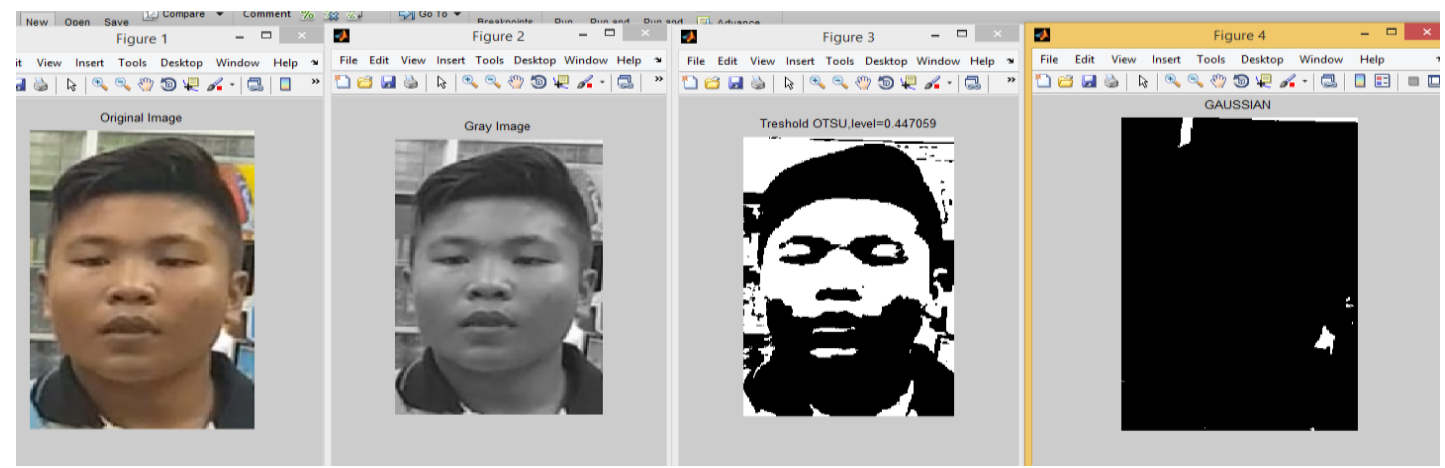

Gambar 3. Hasil Preprocessing Metode Otsu dan Otsu-Gaussian

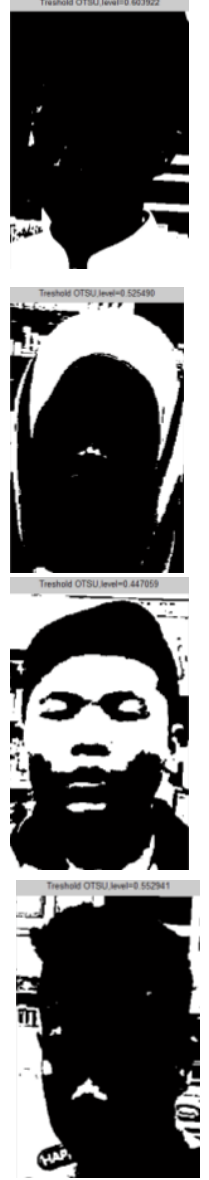

(a)

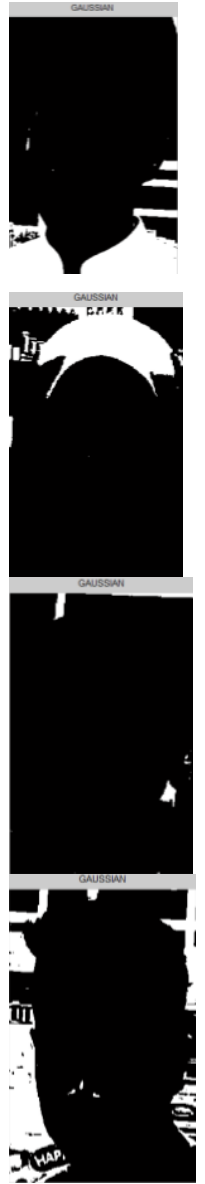

(b)

Gambar 4. Hasil Threshold Otsu (a), Threshold Otsu Gausian (b) 
Berikut hasil perbandingan antara hasil Threshold Otsu dan Threshold Otsu-Gaussian:

\begin{tabular}{|c|c|c|c|}
\hline No & Image Wajah & Otsu & Otsu-Gaussian \\
\hline 1 & Img1 & 0,603922 & 0,6422 \\
\hline 2 & Img2 & 0,525490 & 0,6763 \\
\hline 3 & Img3 & 0,447059 & 0,8659 \\
\hline 4 & Img4 & 0,552941 & 0,6300 \\
\hline 5 & Img5 & 0,411765 & 0,8252 \\
\hline 6 & Img6 & 0,305882 & 0,8899 \\
\hline 7 & Img7 & 0,376471 & 0,8743 \\
\hline
\end{tabular}

Proses segmentasi dan Klasifikasi SVM dalam tahap pengenalan ekspresi wajah tidak dapat dilakukan karena tahapan preprocessing menggunakan threshold otsu dan fungsi gaussian tidak mendapatkan gambar wajah yang jelas dan menghasilkan warna dominan hitam. Hal ini dikarenakan tahapan preprocessing tidak membentuk pola wajah dan ciri yang jelas untuk dilakukan klasifikasi dan dimasukkan ke model SVM.

\section{Kesimpulan dan Saran}

Hasil penerapan metode otsu dan fungsi gaussian dapat digunakan untuk tahapan preprocessing melalui threshold image yang memiliki kualitas gambar yang baik. Metode otsugaussian tidak efektif digunakan untuk preprocessing data yang bersumber dari video atau image dengan kualitas gambar yang kurang baik, sehingga menyulitkan proses pengenalan wajah. Bahkan, penggabungan metode otsu dan fungsi gaussian kurang membantu dalam proses segmentasi untuk hasil video yang memiliki pencahayaan dan posisi wajah yang kurang tepat. Oleh karena itu perlu dilakukan penelitian lebih lanjut untuk perbaikan tahapan preprocessing sehingga memudahkan proses segmentasi dan pengenalan ekspresi wajah. Penelitian ini dapat diperkuat dengan mencari lokasi penelitian dimana kamera CCTV diposisikan tepat pada wajah pelanggan agar memudahkan dalam mendapatkan image wajah yang lebih jelas.

\section{Ucapan Terima Kasih}

Kami mengucapkan banyak terima kasih atas sharing dan ilmu dari teman-teman sejawat Fakultas IImu Komputer Universitas Ichsan Gorontalo.

\section{Daftar Pustaka}

[1] E. Paulus, Paulus, Erik, et al. "Pengenalan Ekspresi Wajah Dalam Waktu Nyata Menggunakan Hausdorff Distance", Bandung: Seminar Nasional Teknologi Informasi, 2015.

[2] H. Husdi, "Pengenalan Ekspresi Wajah Pengguna Elearning Menggunakan Artificial Neural Network Dengan Fitur Ekstraksi Local Binary Pattern Dan Gray Level Co-Occurrence Matrix", IIk. J. IIm., 2016.

[3] Shahrabi Farahani F, "A fuzzy approach for facial emotion recognition". J. Neurol. Sci., vol. 02, no. 2, 2013.

[4] M. Athoillah, M. I. Irawan, dan E. M. Imah, "Study Comparison Of Svm-, K-Nn- And Backpropagation-Based Classifier For Image Retrieval”, hal. 883, 2015.

[5] N. Neneng, K. Adi, dan R. Isnanto, "Support Vector Machine Untuk Klasifikasi Citra Jenis Daging Berdasarkan Tekstur Menggunakan Ekstraksi Ciri Gray Level Co-Occurrence Matrices (GLCM)", J. Sist. Inf. BISNIS, 2016.

[6] A. Riadi, "Pengenalan Plat Nomor Kendaraan Ganjil Genap Menggunakan Metode Support Vector Machine ( SVM )", vol. 10, hal. 168-185, 2014.

[7] F. Roberti de Siqueira, W. Robson Schwartz, dan H. Pedrini, "Multi-scale gray level cooccurrence matrices for texture description", Neurocomputing, 2013.

[8] Prasetyo, "Data Mining Mengolah Data Menjadi Informasi Menggunakan Matlab", Penerbit Andi, 2014.

[9] R. A. Surya, A. Fadlil, dan A. Yudhana, "Ekstraksi Ciri Metode Gray Level Co-Occurrence 
Matrix (GLCM) dan Filter Gabor untuk Klasifikasi citra Batik Pekalongan”, J. Inform., vol. 02, no. 02, hal. 23-26, 2017.

[10] M. Widyaningsih, "Identifikasi Kematangan Buah Apel Dengan Gray Level Co-Occurrence Matrix (GLCM)", J. SAINTEKOM, vol. 6, no. 1, hal. 71-88, 2017.

[11] I. Kononenko dan M. Kukar, "Data Preprocessing", in Machine Learning and Data Mining, 2007.

[12] E. Suryanto dan S. W. Purnami, "Perbandingan Reduced Support Vector Machine dan Smooth Support Vector Machine untuk Klasifikasi Large Data", J. Sains dan Seni ITS, 2015.

[13] J. S. Wibowo, "Deteksi dan Klasifikasi Citra Berdasarkan Warna Kulit Menggunakan HSV", J. Teknol. Inf. Din., vol. 16, no. 2, hal. 118-123, 2011.

[14] H. Gao, W. Xu, J. Sun, dan Y. Tang, "Multilevel thresholding for image segmentation through an improved quantum-behaved particle swarm algorithm", IEEE Trans. Instrum. Meas., 2010.

[15] E. P. Mandyartha dan C. Fatichah, "Three-level Local Thresholding Berbasis Metode Otsu untuk Segmentasi Leukosit pada Citra Leukemia Limfoblastik Akut", J. Buana Inform., vol. 7, no. 1, hal. 43-54, 2016. 